\title{
Adiabatic Heating of Austenitic Stainless Steels at Different Strain Rates
}

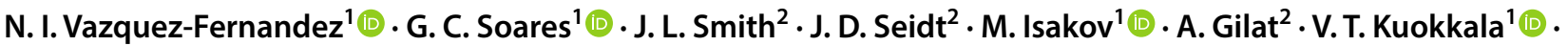 \\ M. Hokka' ${ }^{10}$
}

Received: 29 March 2019 / Accepted: 12 June 2019 / Published online: 20 June 2019

(C) The Author(s) 2019

\begin{abstract}
This work focuses on the effect of strain rate on the mechanical response and adiabatic heating of two austenitic stainless steels. Tensile tests were carried out over a wide range of strain rates from quasi-static to dynamic conditions, using a hydraulic load frame and a device that allowed testing at intermediate strain rates. The full-field strains of the deforming specimens were obtained with digital image correlation, while the full field temperatures were measured with infrared thermography. The image acquisition for the strain and temperature images was synchronized to calculate the Taylor-Quinney coefficient $(\beta)$. The Taylor-Quinney coefficient of both materials is below 0.9 for all the investigated strain rates. The metastable AISI 301 steel undergoes an exothermic phase transformation from austenite to $\alpha$ '-martensite during the deformation, which results in a higher value of $\beta$ at any given strain, compared to the value obtained for the more stable AISI 316 steel at the same strain rate. For the metastable 301 steel, the value of $\beta$ with respect to strain depends strongly on the strain rate. At strain rate of $85 \mathrm{~s}^{-1}$, the $\beta$ factor increases from 0.69 to 0.82 throughout uniform elongation. At strain rate of $10^{-1} \mathrm{~s}^{-1}$, however, $\beta$ increases during uniform deformation from 0.71 to a maximum of 0.95 and then decreases to 0.91 at the start of necking.
\end{abstract}

Keywords Dynamic testing · Hopkinson bar · Digital image correlation · Thermal imaging · Taylor-Quinney coefficient · Austenitic stainless steels $\cdot$ Strain-induced phase transformation

N. I. Vazquez-Fernandez

naiara.vazquez@tuni.fi

G. C. Soares

guilherme.correasoares@tuni.fi

J. L. Smith

smith.6575@osu.edu

J. D. Seidt

seidt.2@osu.edu

M. Isakov

matti.isakov@tuni.fi

A. Gilat

gilat.1@osu.edu

V. T. Kuokkala

veli-tapani.kuokkala@tuni.fi

M. Hokka

mikko.hokka@tuni.fi

1 Faculty of Engineering and Natural Sciences (ENS), Engineering Materials Science, Tampere University, Korkeakoulunkatu 6, 33101 Tampere, Finland

2 Dept. of Mechanical and Aerospace Engineering, The Ohio State University, 201 West 19th Ave. Scott Laboratory, Columbus, OH 43210, USA

\section{Introduction}

Austenitic stainless steels have an excellent combination of mechanical properties, weldability, and corrosion resistance that makes them suitable for a wide range of engineering applications. In particular, AISI 301 (EN 1.4318) has recently attracted attention because of its lower nickel content and excellent strain hardening properties. This steel grade is less stable than other widely used austenitic stainless steels, and its microstructure can transform from face-centered-cubic (FCC) austenite to near body-centered-cubic (BCC) $\alpha^{\prime}$-martensite $[1,2]$. Throughout this paper the term "martensite" is used to refer to the above mentioned near BCC $\alpha$ '-martensite. In contrast, AISI 316 (EN 1.4420) is a stable austenitic steel. The mechanical properties of these commercial steels have been widely studied at quasi-static strain rates [3], but their thermomechanical behavior at intermediate and high strain rates still requires further studies. One reason for this is the difficulty of quantifying the effects of adiabatic heating on the material's response at high strain rates. Adiabatic 
heating takes place when the energy used for deforming the material turns into heat, but this heat cannot dissipate fast enough to its surroundings, so the temperature of the material increases. This temperature rise can affect the microstructural evolution and change the active deformation mechanisms and, consequently, have a strong effect on the mechanical response of the material [4, 5]. Moreover, the strain rate that causes a temperature rise high enough to influence the microstructural evolution depends on the thermal and physical properties of the material. The temperature rise can also be affected by a strain-induced phase transformation, which also releases heat and can thus affect the microstructural evolution [6]. The effects of strain rate and temperature on the mechanical response of the material are therefore strongly coupled [7-9].

Measuring the temperature of the sample simultaneously with stress and strain allows the calculation of the Taylor-Quinney coefficient [10-12], also called the $\beta$ factor, in adiabatic conditions. This coefficient defines the fraction of the total plastic work that is released as heat instead of being stored in the microstructure of the specimen as dislocations and other permanent defects. Determining $\beta$ is a challenging but very important task for understanding the effects of strain rate and temperature on the mechanical behavior of materials. The $\beta$ factor of many metallic materials is typically assumed to be constant with a value of approximately 0.9 . However, recent studies have shown that the $\beta$ factor varies with plastic strain and that, in many cases, its value is much lower than 0.9 . For example, Trojanowski et al. [13] and Macdougall [14] measured the surface temperature of a titanium alloy and an aluminum alloy using an infrared radiometer to calculate the $\beta$ factor during high strain rate Split Hopkinson bar tests. The thermal data was validated with a fast response thermocouple, and their results showed that $\beta$ increased with strain from 0.5 to 0.9 . Recent developments in technology enable measuring the thermal full-field data by infrared thermography at high speed, and combining the data with the full-field strain obtained with digital image correlation (DIC) [15, 16]. Knysh et al. [17] obtained the $\beta$ factor for some steels and titanium alloys with local measurements of temperature with an infrared camera and using DIC for the strain analysis. The alloys tested by Knysh et al. indicated a wide range of values for $\beta$, from 0.3 up to 0.8 . Rittel et al. [18] highlighted the current disagreement in the $\beta$ values reported in the literature for several materials, and showed that the value of $\beta$ depends on the loading mode. Whatever the case may be, $\beta$ is influenced by the microstructural evolution of the material, which is typically not constant during plastic deformation $[19,20]$. Therefore, $\beta$ is also a quantifiable measure of the evolution rate of the microstructure and can be used for describing how much and how fast the microstructure changes during deformation.

The $\beta$ factor can be expressed as the ratio of the heat energy increment of the system, $d Q$, and the mechanical work increment, $d W$, as shown in Eq. 1:

$\beta=\frac{d Q}{d W}$

In turn, the mechanical work increment is calculated in an uniaxial case by multiplying the force $F$ and the distance moved by the acting point of the force $(d x)$, which is equivalent to multiplying the stress, $\sigma$, the plastic strain increment, $d \varepsilon_{p}$, and the volume, $V$, of the element as shown in Eq. 2 . Under adiabatic conditions, the released heat can be estimated as the product of the density, $\rho$, the heat capacity, $c$, and the incremental change of temperature $(d T)$ as shown in Eq. 3.

$d W=F d x=\sigma V d \varepsilon_{p}$

$d Q=\rho c V d T$

By combining the above Equations, $\beta$ can be calculated from the stress-strain curve and the temperature increase of the sample, as in (4):

$\beta=\frac{\rho c d T}{\sigma d \varepsilon_{\mathrm{p}}}$

The value used for the heat energy must take into account all sources and losses of heat. In metastable stainless steels, more heat is generated by the exothermic martensitic phase transformation. Furthermore, at lower strain rates, some heat can dissipate to the surroundings leading to heat losses, which, in contrast, in adiabatic conditions reduces to zero. These two statements can be written as:

$d Q=d W-d Q_{l}+d H_{\gamma \rightarrow \alpha^{\prime}}-d E_{s}$

where $d Q_{l}$ includes the heat losses to the surrounding and $d H_{\gamma \rightarrow \alpha^{\prime}}$ is the internal heat release. The last component of Eq. $5, d E_{s}$, is the amount of energy stored in the microstructure as defects, such as dislocations. Accordingly, the Taylor-Quinney coefficient of a material deforming at adiabatic conditions is given by Eq. 6 . This Equation shows an important result; in the case of a metastable microstructure, the heat from the (exothermic) phase transformation directly adds to the value of $\beta$.

$\beta=1+\frac{d H_{\gamma \rightarrow \alpha^{\prime}}-d E_{s}}{d W}$

In this work, the effects of strain rate and adiabatic heating on the metastable AISI 301 steel were studied in detail, whereas the stable AISI 316 steel was used as a reference. These two steels have similar initial microstructures and cold rolling state, but they differ in their chemical compositions, 
Table 1 Chemical composition (wt \%) of the steels tested in this work

\begin{tabular}{llllllllll}
\hline Material & $\mathrm{C}$ & $\mathrm{Si}$ & $\mathrm{Mn}$ & $\mathrm{P}$ & $\mathrm{S}$ & $\mathrm{Cr}$ & $\mathrm{Ni}$ & $\mathrm{N}$ & $\mathrm{Mo}$ \\
\hline 316 & 0.018 & 0.47 & 1.77 & 0.027 & 0.0020 & 20.3 & 8.6 & 0.180 & 0.64 \\
301 & 0.023 & 0.48 & 1.19 & 0.030 & 0.0003 & 17.4 & 6.5 & 0.138 & 0.10 \\
\hline
\end{tabular}

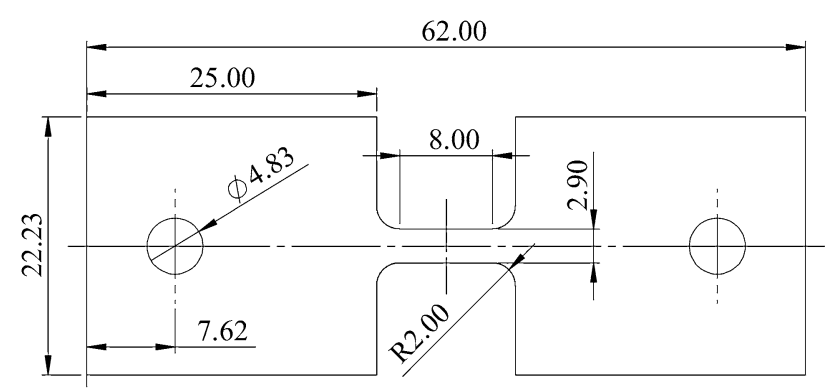

Fig. 1 Specimen geometry for both the high and low strain rate tests. Dimensions are in $\mathrm{mm}$

and therefore the stacking fault energies are different. The evolution of their microstructures with plastic strain is also different due to their distinct deformation mechanisms. The higher stacking fault energy of the stable 316 steel allows easier cross slip of the dislocations and it also retains its austenitic structure during deformation, whereas the low stacking fault energy of the AISI 301 restricts the glide of dislocations to planar slip. The AISI 301 can also undergo strain-induced martensitic phase transformation during deformation. The phase transformation (austenite to martensite) is an exothermal reaction, i.e., it releases heat. The heat produced by this phase transformation will add to the adiabatic heating during deformation at high strain rates, and, as discussed above, this additional heat may contribute to the measured value of the Taylor-Quinney coefficient. The goal of this work is to quantitatively measure the Taylor-Quinney coefficient as a function of strain for the two steel grades and to evaluate the results based on the discussion presented above.

\section{Experimental Setup and Procedure}

\section{Materials and Sample Geometry}

Table 1 summarizes the nominal chemical compositions of the two studied steels. Outokumpu Stainless LTD provided both steels in the same cold rolling state (2B). Both materials initially had an austenitic microstructure. The tension specimens were laser-cut from $2 \mathrm{~mm}$ thick sheets so that the rolling direction is parallel to the loading direction. The materials were tested in as-received condition. Figure 1 shows the specimen geometry.

\section{Mechanical Testing}

For each material, one uniaxial tensile test was carried out at the strain rates of $2.5 \times 10^{-4} \mathrm{~s}^{-1}, 10^{-3} \mathrm{~s}^{-1}, 10^{-2} \mathrm{~s}^{-1}, 10^{-1} \mathrm{~s}^{-1}$, and $85 \mathrm{~s}^{-1}$ using two different experimental setups. Both setups are shown in Fig. 2. The tests at the strain rates up to $10^{-1} \mathrm{~s}^{-1}$ were performed using a servohydraulic Instron 8800 testing machine at Tampere University (Fig. 2a), whereas the tensile tests at the strain rate of $85 \mathrm{~s}^{-1}$ were carried out at the Dynamic Mechanics of Materials Laboratory, in The Ohio State University. These latter tests were carried out using an intermediate rate tensile bar system where a hydraulic actuator loads the specimen (Fig. 2b). In this setup, the load on the sample is measured on a very long transmitted bar, of about $40 \mathrm{~m}$, using semiconductor strain gages near the bar-specimen interface. The long transmitted bar allows the loading pulse to be recorded without the pulse reflected at the back end of the bar overlapping the measured load signal during the intermediate strain rate test. The sample is
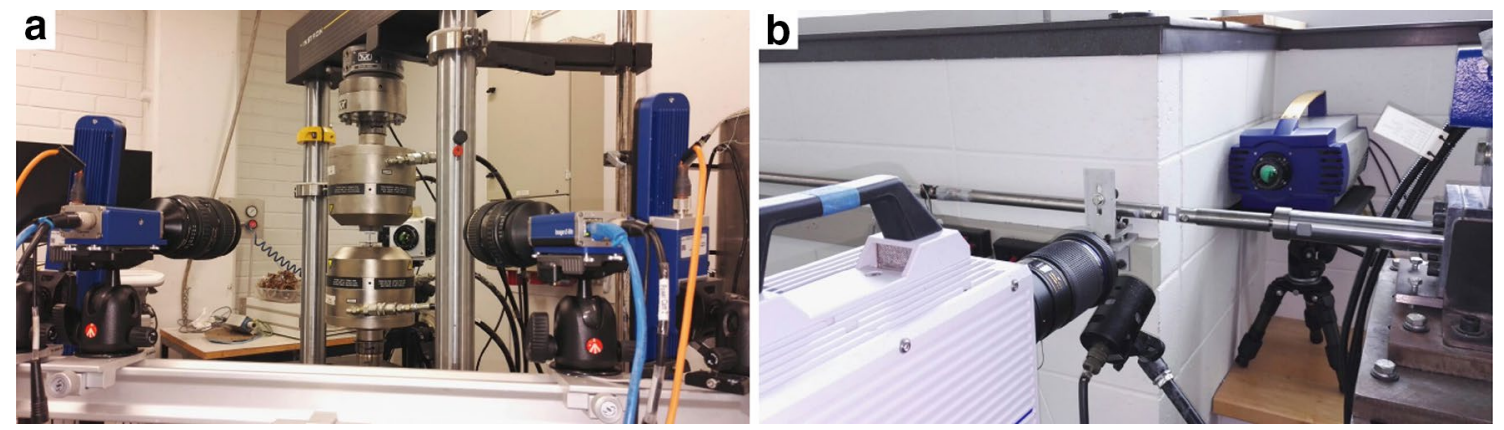

Fig. 2 Experimental setup for the experiments at the strain rates a below $10^{-1} \mathrm{~s}^{-1}$ performed at Tampere University, and $\mathbf{b}$ at $85 \mathrm{~s}^{-1}$ performed at Ohio State University 
Table 2 Experimental parameters for the data acquisition and data processing of DIC and IR imaging

\begin{tabular}{|c|c|c|c|c|c|c|}
\hline $\begin{array}{l}\text { Strain rate } \\
\left(\mathrm{s}^{-1}\right)\end{array}$ & Equipment & $\begin{array}{l}\text { Frame rate } \\
(\mathrm{Hz})\end{array}$ & $\begin{array}{l}\text { Optical image resolution and } \\
\text { scale }\end{array}$ & DIC subset size & DIC step size & $\begin{array}{l}\text { IR image resolution and } \\
\text { scale }\end{array}$ \\
\hline $2.5 \times 10^{-4}$ to $10^{-1}$ & Instron & 0.2 to 25 & $1000 \times 1000 \mathrm{pix} 48.19 \mathrm{pix} / \mathrm{mm}$ & 21 pix & 7 pix & $320 \times 256$ pix 4.05 pix $/ \mathrm{mm}$ \\
\hline 85 & $\begin{array}{l}\text { Intermediate } \\
\text { rate tensile bar } \\
\text { system }\end{array}$ & 20000 & $1024 \times 240$ pix $44.97 \mathrm{pix} / \mathrm{mm}$ & 17 pix & 5 pix & $128 \times 44$ pix 6.27 pix $/ \mathrm{mm}$ \\
\hline
\end{tabular}
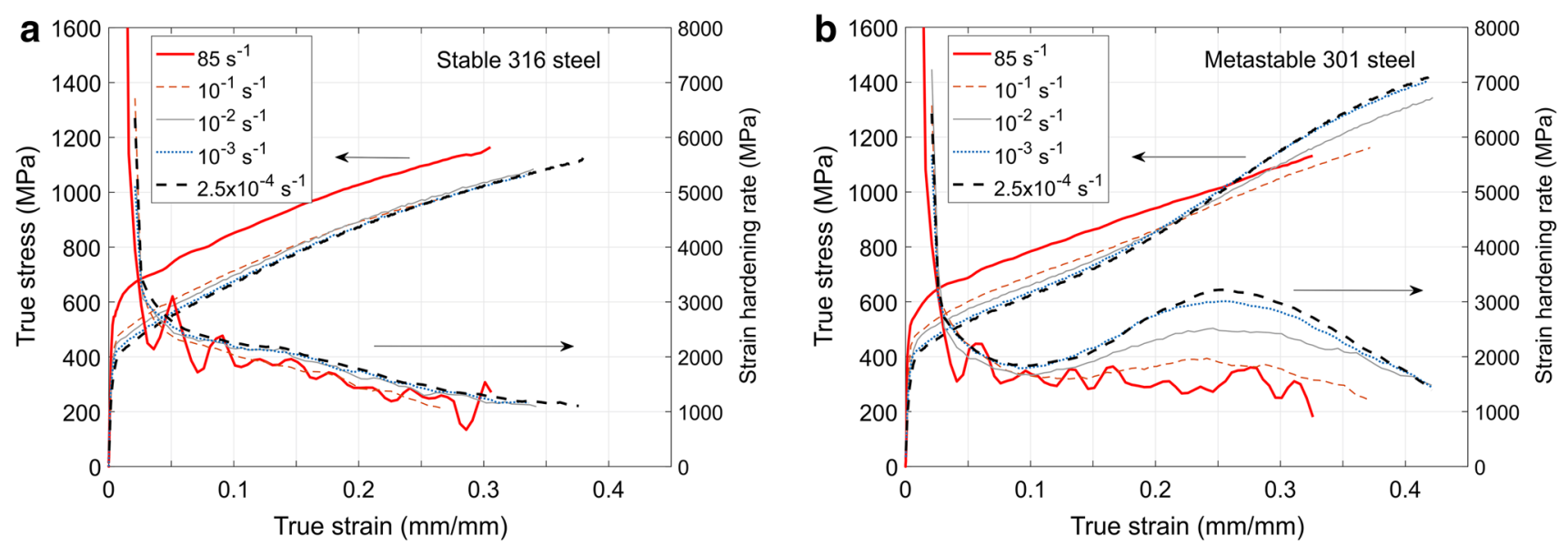

Fig. 3 True stress and strain hardening rate as a function of the true strain at the strain rates of $2.5 \times 10^{-4} \mathrm{~s}^{-1}, 10^{-3} \mathrm{~s}^{-1}, 10^{-2} \mathrm{~s}^{-1}, 10^{-1} \mathrm{~s}^{-1}$, and $85 \mathrm{~s}^{-1}$ for the a stable austenitic stainless steel 316, and b metastable austenitic stainless steel 301

attached mechanically to both the bar and to the hydraulic actuator piston using pins that pass through the hole in the sample and sample holders attached to the bar and to the piston. Further details of the setup can be found in [21].

\section{Simultaneous Full-Field Strain and Temperature Measurements}

The full strain fields were calculated from the images of the deforming specimen using a commercial Digital Image Correlation software program (Lavision, Davis10). The images at the strain rates below $10^{-1} \mathrm{~s}^{-1}$ were recorded using two 5MPix E-lite cameras with $100 \mathrm{~mm}$ lenses, whereas the tests at the strain rate of $85 \mathrm{~s}^{-1}$ were recorded using a Photron SA1.1 high-speed camera with a $180 \mathrm{~mm}$ lens. In this setup, the strain field was only $2 \mathrm{D}$, whereas in the lower-rate tests, the use of two cameras allowed 3D displacements to be computed. The front surface of the samples was painted with a white background base color, and fine black speckles were sprayed on top to produce a high contrast pattern. The thermal images were obtained at the same frequency as the visible images from the opposite (non-painted) side of the sample. The thermal images during the tests at low strain rates were recorded using a Telops Fast-IR-M2 K camera, while at the strain rate of $85 \mathrm{~s}^{-1}$ the images were recorded with a Telops Fast-IR-MFA-00083-101 camera. The true surface temperatures of the sample were obtained by calibrating the raw data acquired by the Telops cameras against thermocouple measurements carried out on an externally heated unloaded specimen.

The Davis 10 software (Lavision Inc.) was used to match both the visible and thermal images into the same spatial coordinate system. Table 2 summarizes the parameters used for the visible imaging, the infrared imaging, and for performing the DIC analysis.

\section{Results and Discussion}

Figure 3 shows the true stress-strain curves and the corresponding strain-hardening rate curves for both materials at all the tested strain rates. These curves were plotted until ultimate tensile strength (UTS), after which the equations used for obtaining the true-strain and true-stress are no longer valid as the deformation in the specimen is not uniform. The stress-strain curves for the stable austenitic AISI 316 steel show a parabolic or almost linear stress-strain response at all the strain rates (Fig. 3a). For this material, the flow stress increases with the increasing strain rate, and the shape of the stress-strain curve and the corresponding 


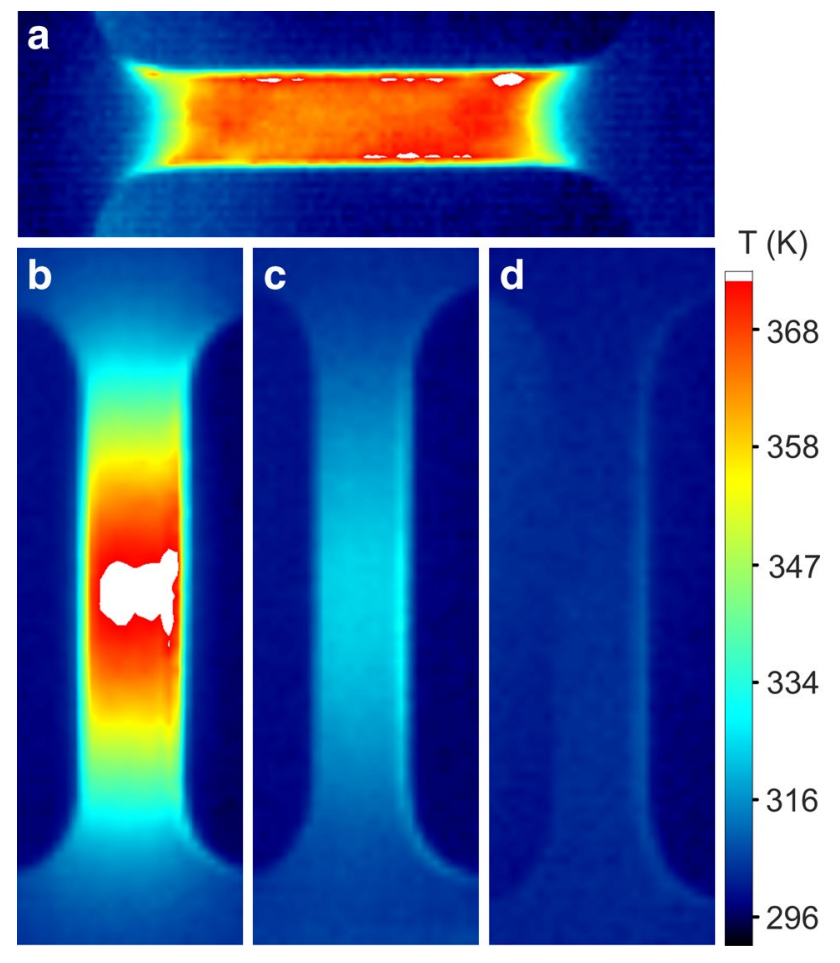

Fig. 4 Temperature maps of the tensile specimen of the metastable 301 steel at the UTS for the strain rates of $\mathbf{a} 85 \mathrm{~s}^{-1}, \mathbf{b} 10^{-1} \mathrm{~s}^{-1}, \mathbf{c}$ $10^{-2} \mathrm{~s}^{-1}$, and d $2.5 \times 10^{-4} \mathrm{~s}^{-1}$

strain-hardening rate remain constant. In contrast, the shape of the stress strain curves of the metastable austenitic AISI 301 steel change with increasing strain rate (Fig. 3b). At the quasi-static strain rate of $2.5 \times 10^{-4} \mathrm{~s}^{-1}$, the flow stress of the material increases significantly at around 0.1 true strain, and the strain-hardening rate increases until it reaches a maximum at around 0.25 true strain, after which the hardening rate starts decreasing. The increase in the strain-hardening rate can be related to the phase transformation of austenite to martensite, i.e., the transformation of a soft phase into a much stronger phase $[22,23]$. Increasing the strain rate decreases the phase transformation rate, and consequently decreases the strain-hardening rate of the material [24]. At the strain rate of $85 \mathrm{~s}^{-1}$, the shape of the stress-strain curve of the AISI 301 steel is very similar to the one observed for the stable 316 steel.

Figure 4 shows the full-field temperature images obtained from the specimen at UTS for the metastable 301 steel at several strain rates. From these images, one can observe that at the strain rate of $85 \mathrm{~s}^{-1}$ the deformation is fully adiabatic, as the temperature field on the gage section is homogeneous, and there is no temperature increase in the grip sections. An increase of temperature in the grip sections would indicate a heat flow away from the deforming gage section, which should not happen if the deformation is adiabatic. At the strain rates of $10^{-1} \mathrm{~s}^{-1}$ and $10^{-2} \mathrm{~s}^{-1}$, however, the temperature of the gage section is not constant, and a maximum temperature can be observed in the middle of the gage section. The temperature along the gage section slowly drops towards the grip sections, and thus, evidence that heat is being conducted from the gage section to the grips. Therefore, the deformation is not fully adiabatic although the temperature of the sample clearly increases. At the strain rate of $2.5 \times 10^{-4} \mathrm{~s}^{-1}$, the temperature does not increase along the gage length during uniform deformation as the heat produced by the phase transformation and by the plastic work is transferred to the surroundings so fast that the temperature of the sample remains constant. Based on measurement data not shown here for the sake of brevity, similar conclusions can be drawn for the stable 316 steel.

Figure 5 shows the full field strain and temperature image pairs of the metastable 301 steel at different strains for the test at the strain rate of $85 \mathrm{~s}^{-1}$. Both the strain and the thermal images show the shear bands formed in the material just before necking. The strain and thermal fields correspond to the opposite sides of the sample. Despite this fact, the shear bands observed in the strain fields match the shear bands observed in the thermal full-field data. Shear bands were similarly observed in the stable 316 steel in both the strain and thermal data.

Figure 6 shows the temperature increase $(\Delta T)$ as a function of true plastic strain at all studied strain rates for both materials. In the lower strain rate tests, heat is conducted away from the gage section to the grip regions, and therefore averaging the temperature of the whole gage section would give values influenced by the heat transfer. This error is minimized by evaluating the increase of the temperature $(\Delta \mathrm{T})$ in a small area near the center of the gage section. That is, the temperature increase was obtained from the failure point of the sample. The $\Delta \mathrm{T}$ for both materials increases with plastic strain for all the strain rates, except for the quasi-static strain rate of $2.5 \times 10^{-4} \mathrm{~s}^{-1}$, for which the temperature increase is zero, as expected. For the stable 316 steel, higher strain rate leads to higher temperature increase at any given true plastic strain. For the metastable 301 steel, $\Delta \mathrm{T}$ increases with strain similarly to the 316 steel for all the strain rates until 0.10 true strain. After that, however, the temperature of the 301 steel increases faster at the strain rate of $10^{-1} \mathrm{~s}^{-1}$ than at $85 \mathrm{~s}^{-1}$. At the strain rate of $10^{-1} \mathrm{~s}^{-1}$, the temperature increases fastest at the plastic strains close to 0.25 , which is approximately the same plastic strain at which the maximum strain hardening occurs. The phase transformation rate is also the highest at those plastic strains, i.e., true strain of 0.25 [24]. The exothermal phase transformation produces excess heat in the 301 alloy, which increases the temperature of the material during deformation. The phase transformation takes place more readily at lower strain rates, and therefore, the samples heat up more at lower strain rates even though the amount of mechanical work is higher at higher strain rates and heat 

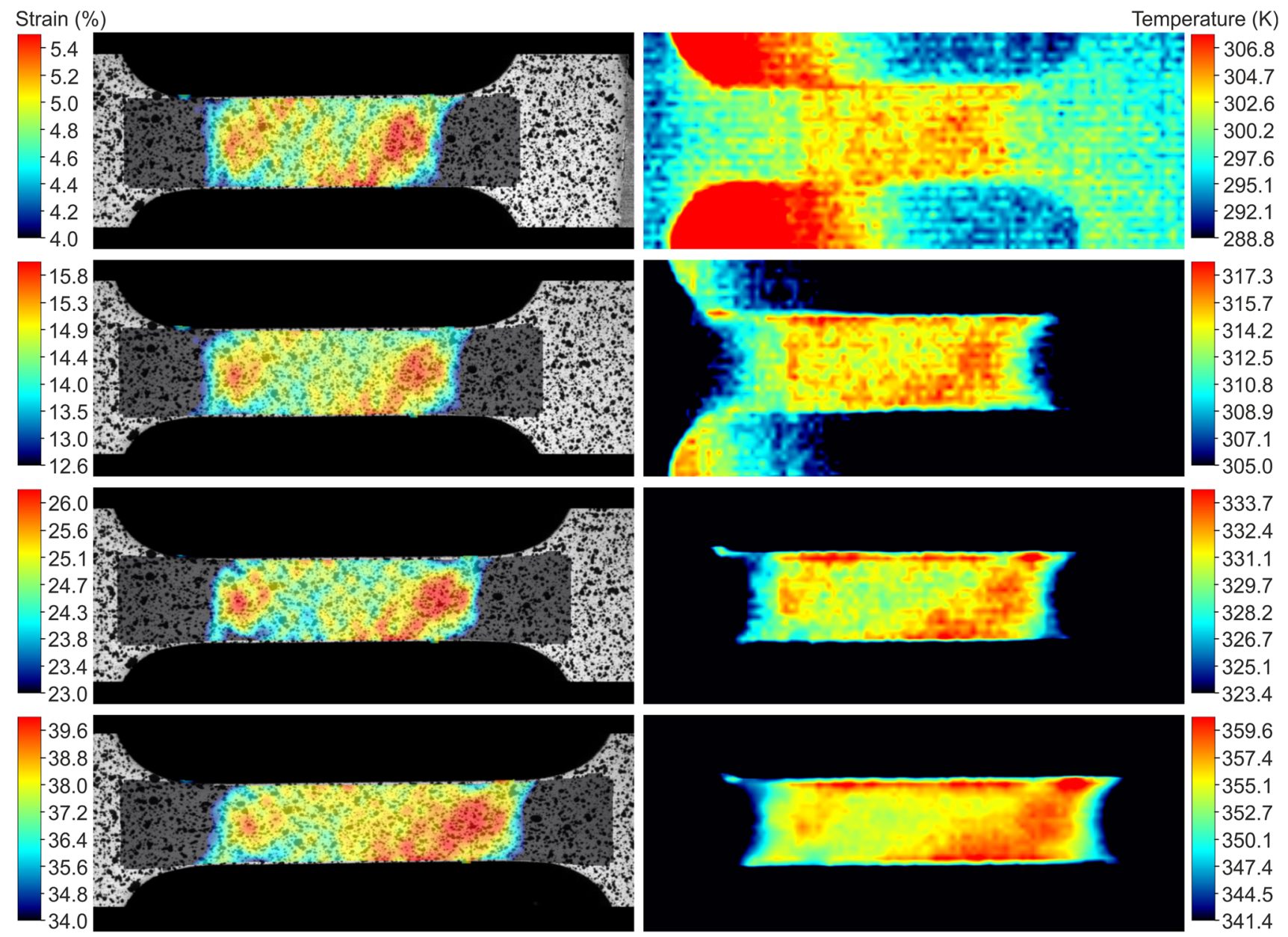

Fig. 5 Full-field strain and temperature data for the metastable 301 steel at the strain rate of $85 \mathrm{~s}^{-1}$ at engineering strain values of a 5\%, b $15 \%$, c $25 \%$, and $\mathbf{d}$ at the end of uniform elongation $(38 \%)$
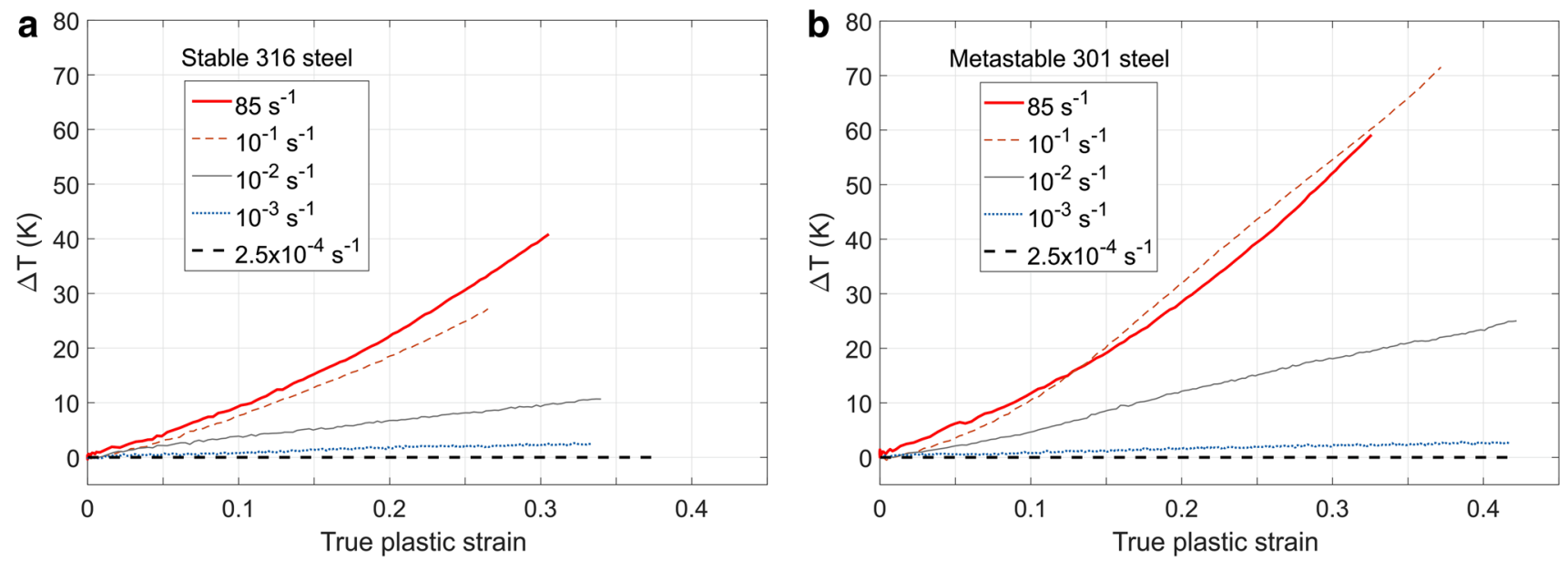

Fig. 6 Temperature increase $(\Delta \mathrm{T})$ as a function of true plastic strain for the a stable 316 steel and $\mathbf{b}$ metastable 301 steel at different strain rates 


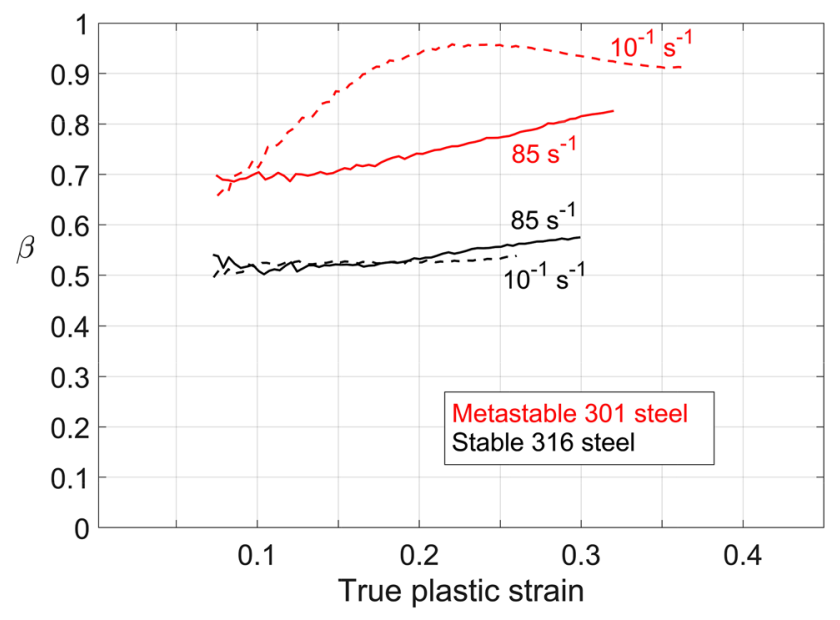

Fig. $7 \beta$ as a function of true plastic strain for the two austenitic steels at the strain rate of $85 \mathrm{~s}^{-1}$ (solid line) and at the strain rate of $10^{-1}$ $\mathrm{s}^{-1}$ (dashed line). The specimen temperature was measured at the final failure location, where adiabatic deformation conditions were assumed for the calculation

transfer away from the specimen may take place at the lower strain rates.

Figure 7 presents the $\beta$ factor for both materials at the strain rate of $85 \mathrm{~s}^{-1}$ (solid line) and at the strain rate of $10^{-1} \mathrm{~s}^{-1}$ (dashed line), and Fig. 8 shows the true stress and temperature as a function of true plastic strain, comprising the data used to obtain $\beta$ in Fig. 7. Since the calculation of the $\beta$ factor at low values of strain is highly sensitive to the noise-to-signal ratio of both stress and thermal data, the values for the $\beta$ factor presented in this work start from true plastic strain values of 0.07 . At the strain rate of $85 \mathrm{~s}^{-1}$ (solid lines), the deformation is fully adiabatic for both materials, and values of $\beta$ are clearly below the 0.9 value that has been widely used for metals [17]. In fact, the $\beta$ factor increases with increasing strain. For the stable 316 steel, $\beta$ increases from 0.50 at true plastic strain of 0.1 to about 0.57 throughout uniform elongation. The $\beta$ factor for the metastable 301 steel has a minimum value of 0.69 at the true plastic strain of 0.10 , and the $\beta$ factor increases up to 0.82 at the UTS. At the highest strain rate, the temperature increase is so high that the phase transformation is significantly reduced. At this strain rate, the $\beta$ factor of the metastable 301 steel behaves similarly to what is observed for the 316 steel, but it has higher values at all strains. In principle, the differences in the $\beta$ factor mean that more energy is converted to heat in the metastable 301. At the strain rate of $10^{-1} \mathrm{~s}^{-1}$ (dashed line), the temperature data was obtained from the final failure location, where the thermal conditions were assumed to be adiabatic for both materials $\left(\mathrm{dQ}_{1}\right.$ is zero in Eq. 5). As discussed earlier, it is evident that at this strain rate the whole specimen gauge length was not deforming adiabatically, but some heat transfer took place near the grip sections (see Fig. 4b). Based on the IR measurements, however, the temperatures in the vicinity of the final failure point were evolving uniformly until necking, indicating that adiabatic deformation conditions were locally achieved at this point. The $\beta$ of the stable 316 steel is not affected by strain rate, although both the flow stress (and thus the amount of plastic work) and temperature increase are lower at the strain rate of $10^{-1} \mathrm{~s}^{-1}$ than at the strain rate of $85 \mathrm{~s}^{-1}$. At strain rate of $10^{-1} \mathrm{~s}^{-1}$, the $\beta$ of the metastable 301 steel increased from 0.71 at the strain of 0.1 to the maximum of 0.95 at strains close to 0.25 , and then decreased to 0.91 at the end of uniform deformation. The maximum value for $\beta$ was observed at the same strain as for both the maximum strain-hardening rate and the maximum phase transformation rate [24]. The two steels have similar mechanical responses at the strain
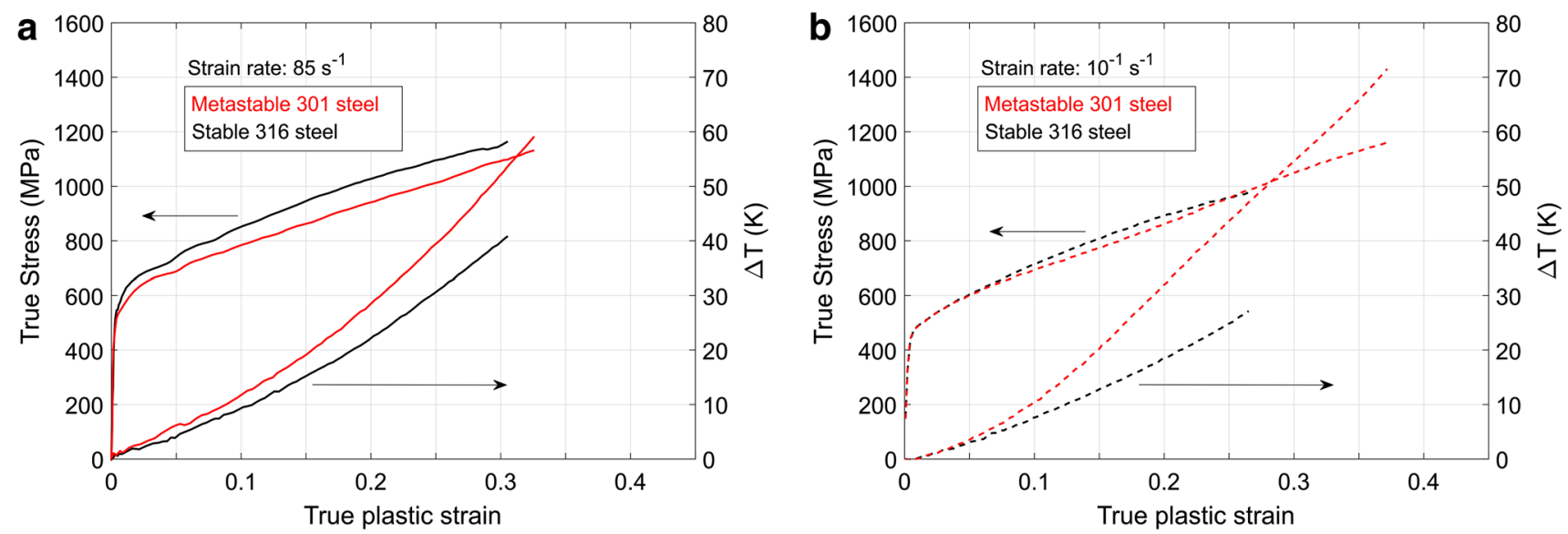

Fig. 8 Stress strain curves and temperature increase $(\Delta \mathrm{T})$ for the two materials at the strain rates of a $85 \mathrm{~s}^{-1}$ and $\mathbf{b} 10^{-1} \mathrm{~s}^{-1}$. The data is the same as in Figs. 3 and 6. The usage of solid and dashed lines is the same as in Fig. 7 
rate of $10^{-1} \mathrm{~s}^{-1}$ (Fig. 8b), but the temperature increase is greater in the metastable 301 steel. The higher temperature increase in the metastable 301 steel can be explained by the exothermic strain-induced martensitic transformation, which adds to the total heat release within the material. The two sources of heating, i.e., heat release from the dislocation motion and heat release from the phase transformation, cannot be measured separately in situ with the current methods. Therefore, the determined values of $\beta$ for the 301 steel do not indicate the classical dislocation theory-based relation between heat generation and the external work. Instead, for the metastable steel, $\beta$ indicates the net heat generation within the material when it is subjected to external loading. A direct consequence of this reasoning is that, in principle, the momentary value of $\beta$ could exceed 1.0, if the heat released from the phase transformation exceeds the amount of plastic work stored in the microstructure. It is, however, unclear, whether such a case would occur in practice.

As is evident in Fig. 4, at lower strain rates the sample does not deform in adiabatic conditions and the $\beta$ factor cannot be calculated with the current method. At those strain rates, there is heat transfer during the test within the sample and to the surroundings (air, test machine), so determining $\beta$ would require either incorporating numerical heat transfer calculations to the analysis or carrying out the experiments with a completely thermally-isolated sample. The former method would be inherently inverse in nature and involve several uncertainties related to the accurate modeling of the experiment, such as the heat transfer coefficients of the various free and contact surfaces as well as heat conduction through several components. The latter method could in principle, give accurate results, but in practice, it is very challenging to carry out an experiment, in which the sample is fully thermally isolated and at the same time subjected to high mechanical forces. Therefore, the determination of $\beta$ below the strain rate of $10^{-1} \mathrm{~s}^{-1}$ is beyond the scope of this paper.

\section{Conclusions}

In this work, the mechanical behavior of two austenitic stainless steels was analyzed in terms of mechanical response and temperature evolution. Simultaneous full-field measurements of strain and temperature were carried out in tensile tests at a wide range of strain rates, ranging from quasi-static to dynamic conditions. The main conclusions of this work can be summarized as the following:

- The current setup and data analysis allow the strain and thermal fields on the specimen to be analyzed simultaneously. Shear bands in the specimen can be observed in both the strain and temperature fields. This indicates that good spatial and temporal synchronization is obtained between the two measurement techniques.

- With the presented full-field temperature measurements, it can be determined whether the sample is tested under fully adiabatic conditions or not. This allows a distinction to be made as to whether the Taylor-Quinney coefficient $(\beta)$ can be determined with the simple equation for adiabatic heating conditions or whether the heat transfer through the sample and to its surroundings has to be accounted for. This work focuses on strain rates involving fully adiabatic deformation conditions (i.e. at and above $10^{-1} \mathrm{~s}^{-1}$ ), while the determination of $\beta$ at lower strain rates is left for future studies.

- For the studied steels, the value of the $\beta$ coefficient varies during the test, increasing with increasing strain, and is below the traditionally assumed value of 0.9 . The $\beta$ coefficient for the stable austenitic steel AISI 316 is significantly lower than the corresponding value for the metastable austenitic steel AISI 301. If it is assumed that the evolution of the microstructure in both steels, AISI 316 and AISI 301, is similar except for the phase transformation occurring in the metastable steel AISI 301, it can be concluded that the difference in the $\beta$ coefficient is due to the exothermic phase transformation taking place in the metastable material.

Acknowledgements This work was partly funded by the Academy of Finland under the Grant 294845. The work carried out at the Dynamic Mechanics of Materials Laboratory, in The Ohio State University, was also partly supported by The Technology Industries of Finland Centennial Foundation, Steel and Metal Producers' Fund.

Open Access This article is distributed under the terms of the Creative Commons Attribution 4.0 International License (http://creativeco mmons.org/licenses/by/4.0/), which permits unrestricted use, distribution, and reproduction in any medium, provided you give appropriate credit to the original author(s) and the source, provide a link to the Creative Commons license, and indicate if changes were made.

\section{References}

1. Rosen A, Jago R, Kjer T (1972) Tensile properties of metastable stainless steels. J Mater Sci 7(8):870-876

2. Talonen J, Hänninen H (2007) Formation of shear bands and strain-induced martensite during plastic deformation of metastable austenitic stainless steels. Acta Mater 55(18):6108-6118

3. Lecroisey F, Pineau A (1972) Martensitic transformations induced by plastic deformation in the $\mathrm{Fe}-\mathrm{Ni}-\mathrm{Cr}-\mathrm{C}$ system. Metall Mater Trans B 3(2):391-400

4. Curtze S, Kuokkala V-T (2010) Dependence of tensile deformation behavior of TWIP steels on stacking fault energy, temperature and strain rate. Acta Mater 58(15):5129-5141

5. Martin S, Wolf S, Martin U, Krüger L, Rafaja D (2016) Deformation mechanisms in austenitic TRIP/TWIP steel as a function of temperature. Metall Mater Trans A 47(1):49-58 
6. Talonen J (2007) Effect of strain-induced $\alpha$ '-martensite transformation on mechanical properties of metastable austenitic stainless steels. Helsinki University of Technology, Helsinki

7. Hokka M (2008) Effects of strain rate and temperature on the mechanical behavior of advanced high strength steels. Tampere University of Technology, Tampere

8. Isakov M (2012) Strain rate history effects in a metastable austenitic stainless steel. Tampere University of Technology, Tampere

9. Vazquez Fernandez N, Isakov M, Hokka M, Kuokkala V-T (2017) Effects of adiabatic heating estimated from tensile tests with continuous heating. In: Proceedings of the 2017 annual conference on experimental and applied mechanics. Indianapolis, Indiana, USA

10. Farren WS, Taylor GI (1925) The heat developed during plastic extension of metals. Proc R Soc Lond Ser A 107(743):422-451

11. Taylor GI, Quinney H (1934) The latent energy remaining in a metal after cold working. Proc R Soc Lond Ser A 143(849):307-326

12. Rittel D (1999) On the conversion of plastic work to heat during high strain rate deformation of glassy polymers. Mech Mater 31(2):131-139

13. Trojanowski A, Macdougall D, Harding J (1998) An improved technique for the experimental measurement of specimen surface temperature during Hopkinson-bar tests. Meas Sci Technol 9:12-19

14. Macdougall D (2000) Determination of the plastic work converted to heat using radiometry. Exp Mech 40(3):298-306

15. Gilat A, Kuokkala V-T, Seidt JD, Smith JL (2017) Full-field measurement of strain and temperature in quasi-static and dynamic tensile tests on stainless steel 316L. Proced Eng 207:1994-1999

16. Smith JL, Seidt JL, Gilat A (2019) Full-field determination of the Taylor-Quinney Coefficient in tension tests of Ti-6Al-4 V at strain rates up to $7000 \mathrm{~s}^{-1}$. Adv Opt Methods Digit Image Correl Exp Mech 3:133-139

17. Knysh P, Korkolis YP (2015) Determination of the fraction of plastic work converted into heat in metals. Mech Mater 86:71-80

18. Rittel D, Zhang L, Osovksi S (2017) The dependence of the Taylor-Quinney coefficient on the dynamic loading mode. J Mech Phys Solids 107:96-114

19. Rosakis P, Rosakis AJ, Ravichandran G, Hodowany J (2000) A thermodynamic internal variable model for the partition of plastic work into heat and stored energy in metals. J Mech Phys Solids 48:581-607

20. Rusinek A, Klepaczko J (2009) Experiments on heat generated during plastic deformation and stored energy for TRIP steels. Mater Des 30(1):35-48

21. Seidt J, Kuokkala V-T, Smith J, Gilat A (2017) Synchronous fullfield Strain and temperature measurement in tensile tests at low, intermediate and high strain rates. Exp Mech 57(2):219-229

22. Larour P, Verleysen P, Dahmen K, Bleck W (2013) Strain rate sensitivity of pre-strained AISI 301LN2B metastable austenitic stainless steel. Steel Res Int 84(1):72-88

23. Soares GC, Gonzalez BM, Santos LDA (2017) Strain hardening behavior and microstructural evolution during plastic deformation of dual phase, non-grain oriented electrical and AISI 304 steels. Mater Sci Eng, A 684:577-585

24. Talonen J, Hänninen H, Nenonen P, Pape G (2005) Effect of strain rate on the strain-induced $\gamma \rightarrow \alpha^{\prime}$-martensite transformation and mechanical properties of austenitic stainless steels. Metall Mater Trans A 36(2):421-432

Publisher's Note Springer Nature remains neutral with regard to jurisdictional claims in published maps and institutional affiliations. 